\title{
Successful Treatment of Neglected Clubfeet in 10 Cases Using Ponseti Method, with Outcomes after 8 Years
}

ISSN: 2576-8875

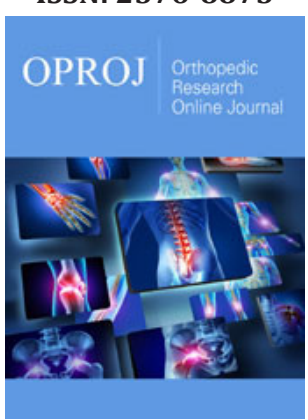

*Corresponding author: Angela Evans, Discipline of Podiatry, School of Science, Health and Engineering, Melbourne, Australia

Submission: 㘹 January 27, 2020

Published: 侮February 05, 2020

Volume 6 - Issue 4

How to cite this article: Angela Evans. Successful Treatment of Neglected Clubfeet in 10 Cases Using Ponseti Method, with Outcomes after 8 Years. Ortho Res Online J. 6(4). OPROJ.000644.2020.

DOI: $10.31031 /$ OPROJ.2020.06.000644

Copyright@: Angela Evans, This article is distributed under the terms of the Creative Commons Attribution 4.0 International License, which permits unrestricted use and redistribution provided that the original author and source are credited.

\author{
Mazharul Islam ${ }^{1}$, Mamun Chowdhury ${ }^{2}$ and Angela Evans ${ }^{3 *}$ \\ ${ }^{1}$ Walk for Life Physiotherapist, Bhola General Hospital, Bhola, Bangladesh \\ ${ }^{2}$ Walk for Life Clinical Director, Rajshahi Medical College Hospital, Bangladesh \\ ${ }^{3}$ Discipline of Podiatry, School of Science, Health and Engineering, Melbourne, Australia
}

\begin{abstract}
Background: Children with untreated clubfeet (CTEV) aged one year or older are usually walking on grossly deformed feet. Typically, they have been regarded as being 'too old' for treatment with the 'gold standard' Ponseti method. These children will rarely receive surgical correction, associated with poorer long-term results, and have a high probability of remaining disabled and impoverished for life. Treatment of older children with Ponseti method has been reported, and this case series shows the possible and positive outcomes in 10 Bangladeshi children, with minor modification of the original Ponseti method.
\end{abstract}

Aims: This case series aimed to report the results of treatment of neglected clubfoot in older children in rural Bangladesh, with follow up extended to eight years

Methods: Ten children with untreated/neglected clubfeet aged between 1-11 years were availed a modified Ponseti method treatment by a WFL physiotherapist in a rural region of Bangladesh.

Results: All children had functioning feet enabling them to walk, and had disabled lives transformed with application of low-cost treatment beginning at a later age. More resources were required (plaster bandage) for the longer legs, but compliance was enhanced by children's understanding and desire for correction. Pictorial posters were aspirational for both the parents and children.

Conclusion: WFL has successfully treated over 25,000 babies and young children with CTEV since 2009. The results of treating neglected cases in Bangladesh have not been previously recorded. Whilst treatment for CTEV is ideally commenced prior to six months of age, neglected CTEV in older children should be managed with Ponseti method principles as a first line approach. Full correction may be achieved at low cost and low risk.

Keywords: Neglect; Ponseti; Clubfoot; Outcomes

\section{Introduction}

Globally, the number of children with congenital clubfoot deformity (congenital talipes equino varus, CTEV) receiving treatment has increased in the last decade [1]. A biennial survey of 58 low-and-middle-income-countries (LMICs), where $90 \%$ of CTEV births occur, found that in 2009 approximately 5,000 children with CTEV received treatment, increasing to 32,000 by 2017 . Whilst impressive growth, the portion of children with CTEV in LMICs receiving treatment, was estimated as just 15 percent [2,3]. Of the 32,000 children enrolled for treatment in LMICs in 2017, 78\% were aged less than one year, and 95\% were aged less than two years. The number of children with CTEV receiving treatment in LMICs has increased, with most beginning treatment at a younger age. Overall, however, less than 20 percent of affected children accessed treatment, and enormous need and preventable disability continues [2].

Children with untreated clubfeet who are older than one year of age and walking on grossly deformed feet, have typically been regarded as having CTEV deformity that is too rigid for management with the non-surgical Ponseti method [4,5]. These same children will rarely receive surgical correction, due to both cost and access. Given that surgery is associated with poor long-term results [6], a dilemma arises when presented with older children in LMICs with neglected clubfeet.

In addition to advancing disability and impairment, it has been reported that neglected clubfeet in LMICs, is associated with less employment options, and reduced marriage prospects, a situation which is magnified for females [7]. In LMICs the parents' education 
level, and literacy are often low, especially in women and girls which is very relevant for infant and maternal health, and can result in neglect of clubfoot deformity, which is ideally treated before six months of age $[8,9]$. This may also be impacted by especially scant health care services in rural regions of LMICs.

Walk for Life (WFL) is the National Clubfoot Project of Bangladesh, a not-for-profit aid project, which has conscientiously shared findings by publication [9-13]. Since 2009, WFL have treated over 25,000 Bangladeshi children with CTEV, by establishing 32 clinics across Bangladesh to enable access to clubfoot care, which was provided at no cost [14]. Neglected cases of clubfoot deformity in children aged between one and 11 years living in rural Bangladesh, have been treated using modified Ponseti method, enabling these older children to walk. This case series aimed to report the results of treatment of neglected clubfoot in older children in rural Bangladesh, with follow up extended to eight years.

\section{Case Series Presentation}

Table 1 presents 10 cases of healthy children treated for clubfoot deformity with mean age of 3.8 years (range: 1 to 11 years). Seven of the 10 cases were male, and eight cases had bilateral clubfeet. None had received any form of prior treatment when they presented at the WFL clinic at Bhola General Hospital in southern Bangladesh. All cases were assessed and treated by a WFL physiotherapist, who adopted the Ponseti method principles in these older children, with extended manipulation time ( 2 to 3 minutes) before plaster cast application. Each cast was changed weekly, as feasible.
Table 1: The age range categories of the 10 cases at the beginning of clubfoot treatment.

\begin{tabular}{|c|c|c|c|}
\hline Age range (years) & $1-2$ & $3-7$ & $8-11$ \\
\hline No. cases & 4 & 5 & 1 \\
\hline
\end{tabular}

Table 2: Proxy indicators of affluence, housing materials and father's occupations.

\begin{tabular}{|c|c|c|c|}
\hline House material & Brick & Tin & Mud \\
\hline No. cases & 1 (orphanage) & 8 & 1 \\
\hline Father's occupation & Rickshaw puller & Shop keeper & Other \\
\hline No. cases & 3 & 3 & $\begin{array}{c}\text { Fisherman 1 } \\
\text { Business 1 } \\
\text { Day labour 1 } \\
\text { Orphan 1 }\end{array}$ \\
\hline
\end{tabular}

Table 1 further displays the clubfoot case series by age at first visit. Table 2 collates proxy indicators of affluence, including house construction material, and father's occupations. Table 3 displays the clinical data. The mean number of corrective plaster casts was 6 (range 4 to 8). An Achilles tenotomy was performed bilaterally in $6 / 10$ cases, unilaterally in $1 / 10$ cases, and $3 / 10$ cases did not undergo a tenotomy. The time from application of the first corrective cast to beginning the maintenance foot abduction brace (FAB) use was 3.1 months (range: 1 to 7 months). The average initial severity assessment (Pirani score) was 5.4/6.0 (range: 5.0 to 6.0). The average severity assessment prior to the tenotomy was 2.1/6.0 (range: 1.5 to 3.0). The average final severity assessment was $0.5 / 6.0$ (range: 0.0 to 1.5 ).

Table 3: Clincal data.

\begin{tabular}{|c|c|c|c|c|c|c|c|c|c|c|c|c|c|}
\hline \multirow[b]{2}{*}{ Case } & \multirow[t]{2}{*}{$\begin{array}{c}\text { Initial } \\
\text { Age (years) }\end{array}$} & \multirow[t]{2}{*}{$\begin{array}{c}\text { Sex } \\
\text { M/F) }\end{array}$} & \multirow[t]{2}{*}{$\begin{array}{l}\text { Foot } \\
\text { Type }\end{array}$} & \multirow[t]{2}{*}{$\begin{array}{l}\text { No. } \\
\text { Casts }\end{array}$} & \multirow[t]{2}{*}{ PAT } & \multirow[t]{2}{*}{$\begin{array}{l}\text { 1st Cast to } \\
\text { FAB (Months) }\end{array}$} & \multirow[t]{2}{*}{$\begin{array}{c}\text { Review } \\
\text { Age (Years) }\end{array}$} & \multicolumn{2}{|c|}{$\begin{array}{l}\text { Initial Severity } \\
\text { Score }\end{array}$} & \multicolumn{2}{|c|}{$\begin{array}{c}\text { Severity Score } \\
\text { at PAT }\end{array}$} & \multicolumn{2}{|c|}{$\begin{array}{c}\text { Final Severity } \\
\text { Score }\end{array}$} \\
\hline & & & & & & & & $\mathbf{L}$ & $\mathbf{R}$ & $\mathbf{L}$ & $\mathbf{R}$ & $\mathbf{L}$ & $\mathbf{R}$ \\
\hline 1 & 1 & $\mathrm{~F}$ & Both & 7 & $Y$ & 3 & 9 & 6 & 6 & 1.5 & 1.5 & 0 & 0 \\
\hline 2 & 3 & M & Right & 6 & Y & 2 & 11 & $\mathrm{n} / \mathrm{a}$ & 5 & $\mathrm{n} / \mathrm{a}$ & 2 & $\mathrm{n} / \mathrm{a}$ & 0 \\
\hline 3 & 2 & F & Both & 5 & Y & 7 & 10 & 5 & 5 & 1.5 & 1.5 & 0 & 0 \\
\hline 4 & 4 & $\mathrm{~F}$ & Both & 6 & $Y$ & 3 & 12 & 6 & 6 & 3 & 3 & 1.5 & 1.5 \\
\hline 5 & 1 & M & Both & 8 & $\mathrm{~N}$ & 2 & 9 & 5 & 5 & $\mathrm{n} / \mathrm{r}$ & $\mathrm{n} / \mathrm{r}$ & 1 & 1 \\
\hline 6 & 3 & $\mathrm{M}$ & Both & 7 & Y & 3 & 11 & 5.5 & 5.5 & 2.5 & 2.5 & 0 & 0 \\
\hline 7 & 4 & $\mathrm{M}$ & Both & 6 & Y & 3 & 12 & 5 & 5 & 2 & 2 & 0 & 0 \\
\hline 8 & 1 & M & Both & 5 & Y & 4 & 6 & 5.5 & 5.5 & 2.5 & 2.5 & 1 & 1 \\
\hline 9 & 6 & M & Both & 4 & $\mathrm{~N}$ & 1 & 11 & 5.5 & 5.5 & $\mathrm{n} / \mathrm{r}$ & $\mathrm{n} / \mathrm{r}$ & 1 & 1 \\
\hline 10 & 11 & M & Left & 5 & $\mathrm{~N}$ & 2.5 & 14 & 4.5 & $\mathrm{n} / \mathrm{a}$ & 1 & $\mathrm{n} / \mathrm{a}$ & 0.5 & $\mathrm{n} / \mathrm{a}$ \\
\hline
\end{tabular}

Abbreviations: PAT: Percutaneous Achilles Tenotomy; FAB: Foot Abduction Brace

NB: $n$ /a-data not relevant for 2 unilateral cases; $n / r$-data not recorded.

Figure 1 depicts a girl aged four years with neglected and marked clubfoot deformity (Figure 1a \& 1b). The family were very poor, living in a mud house, and the father pulling a rickshaw to support the family. Initial casting was applied weekly after sustained manual stretching and corrective manipulation of the foot (Figure 1c). Six serial casts were required, following which the initial severity score $6 / 6$ was reduced to $3 / 6$ bilaterally. Following PAT and stabilisation casting for 3 weeks, the severity score was $1.5 / 6$, and the first FAB was fitted (Figure 1d). Ten follow up visits have occurred since the end of FAB use, and she has been able to 
walk to school and become literate and numerate (Figure 1e). This case had eight year follow up overall. The final image (Figure 1d) shows the girl at age 12 years, standing on plantigrade and flexible feet, adjacent to her 'before and after' treatment pictures on a WFL public education poster.
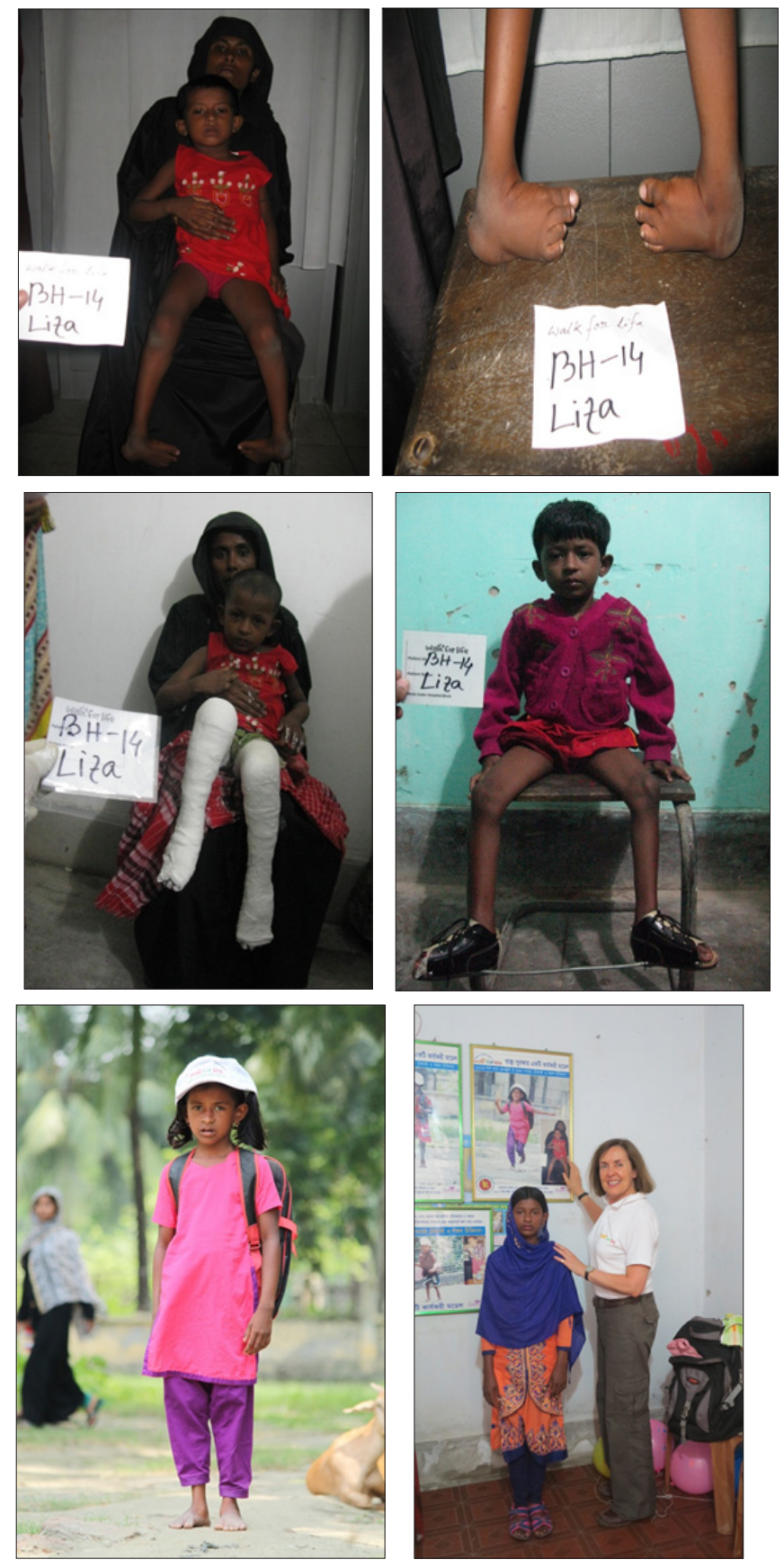

Figure 1: Neglected CTEV presentation in a girl aged 4 to 12 years
a. Four year old girl at initial presentation
b. Neglected clubfeet at initial presentation
c. First corrective casts
d. Fitted with FAB
e. Walking to school with corrected feet at age 7 years
f. Review of feet at age 12 years 
Figure 2 shows an impoverished boy aged four years with neglected clubfoot deformity (Figure $2 \mathrm{a}$ ). He lived with his family in a small village in a house made from tin. His father is a labourer. This case was instrumental in the authors' learning for management of neglected clubfoot deformity in older children. Six serial casts following stretch/manipulation (Figure $2 \mathrm{~b}$ ), preceded the PAT and FAB use (Figure $2 c$ ). The initial severity score of $5 / 6$ reduced to $2 / 6$ with casting, and following PAT was $0 / 6$. Figure $2 \mathrm{~d}$ at the two year follow up shows the boy's corrected feet at age six years.
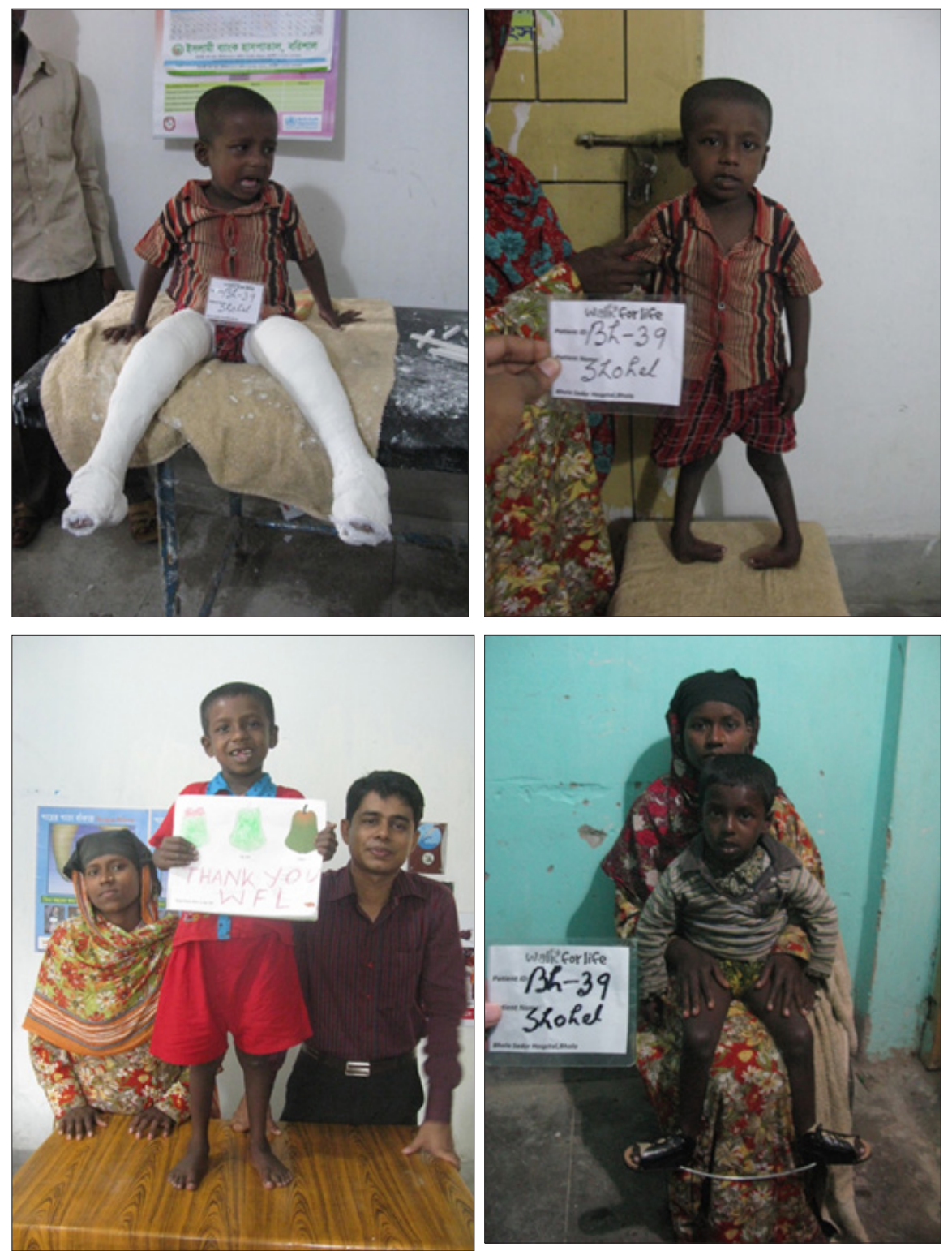

Figure 2: A boy with neglected CTEV aged 4 to 12 years

a. Four year old boy at initial presentation with neglected clubfeet

b. First corrective casts applied

c. FAB fitted for maintenance of deformity correction

d. A happy and mobile 6 year old boy with full correction of his neglected clubfoot deformit

Figure 3a shows two six-year-old boys. The boy from Figure 2, following his clubfoot treatment, and a boy from the same village with neglected clubfeet. This boy's father was another rickshaw puller, and the family lived in a tin house. The treatment commenced when aged six years, and required only four corrective casts, and no PAT before the maintenance FAB was fitted. The initial severity score $5.5 / 6$ was reduced to $1 / 6$ when the FAB was fitted. Figure $3 b$ shows the boys aged 11 and 12 years, walking with functional feet. They play soccer and wear normal shoes. 

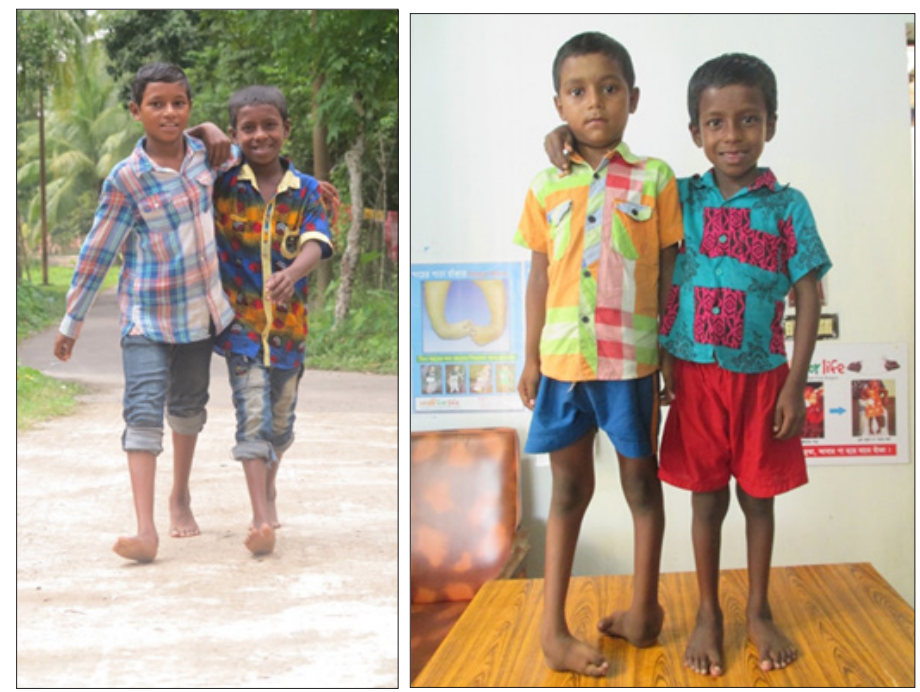

Figure 3: A boy whose neglected clubfeet were treated from ages 6 to 11 years

a. Two 6 year old boys; neglected clubfeet (left), and corrected neglected clubfeet (right, case from Figure 2)

b. The same boys, five years later. Both attend school and play soccer. Both neglected cases had assured lifelong disability prior to treatment, rendering them active and potentially productive.

\section{Discussion}

The minimally invasive Ponseti method is globally accepted as the first line of treatment for CTEV and has achieved excellent results in children with idiopathic CTEV aged $\leq 2$ years [15-17]. However, the upper age limit for the Ponseti treatment has not been defined $[18,19]$. A recent systematic review examined the efficacy of the Ponseti method in older children with neglected CTEV concluding that neglected CTEV should trial of ponseti treatment, irrespective of the severity of the deformity, and that the upper age limit for successful outcomes remains uncertain [20]. The main modifications that have been incorporated when using the Ponseti method in older children are increased manipulation time [18,21], longer cast duration [21], and reduced foot abduction with the FAB [18].

This clinical case series of 10 cases with neglected clubfoot from a remote WFL clinic in Bangladesh, identified the following main points:

a) increased manipulation time (2 to 3 minutes) before each cast application

b) much more plaster was required/case due to increased leg length/size/cast strength, and $7 / 10$ cases required $\geq 6$ casts

c) very good treatment compliance and understanding, despite the children being less mobile with leg casts. Posters depicting other older children 'before and after' treatment of neglected clubfeet were encouraging.

d) the authors also posit the benefits of weight-bearing activity post-casting may assist ankle range, dorsiflexor strength, musculoskeletal loading forces.
Previous studies addressing the older child with neglected clubfoot and results of Ponseti method include a cohort aged 1 to 9 years, which used Ponseti method with modified manipulations (5 to 10 minutes) for more stretching of the soft tissues, which reduced the number of corrective casts [21]. Further, casts were changed every two weeks, and corrected the foot to 30 to 40 degrees abduction (rather than 70 degrees). The final correction was good for the forefoot and midfoot, but five cases required a posterior release of the hindfoot.

Despite the Ponseti method being known for 50 years, the upper age limit at which the Ponseti method can be successfully applied remains uncertain. It has been demonstrated that the Ponseti method achieves good results in children with neglected CTEV at an older age $[18,19]$. However, the protocol for such older cases has not been standardised for repeatable outcomes.

Future considerations to define the upper age limit for Ponseti method effectiveness will include:

a) standardised clinical protocol, with modifications defined by age, eg

b) manipulation times

c) cast type (long or short leg)

d) duration of each cast

e) equinus correction (tenotomy or Achilles lengthening)

f) FAB (or ankle foot orthosis)

g) increased sample sizes

h) longer term follow-up, with treatment failure defined. 
While the Ponseti method is designated 'non-surgical', those experienced in the field find that some surgery may be required, viz. tenotomy (90\%), tibialis anterior tendon transfer (15 to 40\%), repeat tendo Achilles lengthening (TAL), and plantar fasciotomy for some relapsed cases [22]. Ponseti treatment for neglected CTEV has had encouraging results in terms of attaining a functional and visually acceptable foot and lessening the extent of surgery in cases where full correction is not achieved. Thus, neglected CTEV in children presenting at an older age should undergo Ponseti treatment initially, irrespective of the severity of the deformity. Finally, the upper age limit at which successful outcomes can be reached, remains uncertain [20].

\section{Acknowledgement}

All photographs had parent consent. The authors gratefully acknowledge the following groups and individuals: all participating parents and children; Walk for Life in Bangladesh; Bangladesh Government; The People's Republic of Bangladesh.

\section{References}

1. Owen RM, Kembhavi G (2012) A critical review of interventions for clubfoot in low and middle-income countries: Effectiveness and contextual influences. J Pediatr Orthop B 21(1): 59-67.

2. Owen RM, Capper B, Lavy C (2018) Clubfoot treatment in 2015: A global perspective. BMJ Global Health 3(4): e000852.

3. Smythe T, Kuper H, Macleod D, Foster A, Lavy C (2016) Birth prevalence of congenital talipes equinovarus in low- and middle-income countries: A systematic review and meta-analysis. Trop Med Int Health 22(3): 269285.

4. Ponseti I (1992) Treatment of congenital club foot. J Bone Joint Surg Am 74(3): 448-454.

5. Noonan K, Ponseti I (2008) Technique in the treatment of clubfoot.

6. Morcuende JA, Dolan LA, Dietz FR, Ponseti IV (2004) Radical reduction in the rate of extensive corrective surgery for clubfoot using the Ponseti method. Pediatrics 113(2): 376-380.

7. McElroy T, Konde-Lule J, Neema S, Gitta S (2007) Understanding the barriers to clubfoot treatment adherence in Uganda: A rapid ethnographic study. Disabil Rehabil 29(11-12): 845-855.

8. Banskota B, Banskota AK, Regmi R, Rajbhandary T, Shrestha OP, et al. (2013) The Ponseti method in the treatment of children with idiopathic clubfoot presenting between five and ten years of age. Bone Joint J 95$\mathrm{B}(12):$ 1721-1725.

9. Evans AM, Chowdhury MMH, Kabir MH, Rahman MF (2016) Walk for life-the national clubfoot project of Bangladesh: The four-year outcomes of 150 congenital clubfoot cases following Ponseti method. J Foot Ankle Res 9(1): 42.

10. Evans A, Chowdhury M, Rana S, Rahman S, Mahboob AH (2017) 'Fast cast' and 'needle Tenotomy' protocols with the Ponseti method to improve clubfoot management in Bangladesh. Journal of Foot and Ankle Research 10(1): 49.

11. Ford-Powell VA, Barker S, Khan MSI, Evans AM, Deitz FR (2013) The Bangladesh clubfoot project: The first 5000 feet. J Pediatr Orthop 33(4): e40-44.

12. Perveen R, Evans AM, Ford-Powell V, Dietz FR, Barker S, et al. (2014) The Bangladesh clubfoot project: Audit of 2-year outcomes of Ponseti treatment in 400 children. J Pediatr Orthop 34(7): 720-725.

13. Evans AM, Perveen R, Ford-Powell VA, Barker S (2014) The Bangla clubfoot tool: A repeatability study. J Foot Ankle Res 7(1): 27.

14. Evans AM, Mamun Chowdhury, Leila Karimi, Abdur Rouf, Shams Uddin et al. (2020) Factors affecting parents to "Drop-Out" from Ponseti method and children's clubfoot relapse. OPROJ Crimson Publishers 6(3): 601-609.

15. Van Bosse HJ (2011) Ponseti treatment for clubfeet: An international perspective. Curr Opin Pediatr 23(1): 41-45.

16. Cooper DM, Dietz FR (1995) Treatment of idiopathic clubfoot. A thirtyyear follow-up notes. J Bone Joint Surg Am 77(10): 1477-1489.

17. Smith PA, Kuo KN, Graf AN, Krzak J, Flanagan A, et al. (2013) Long-term results of comprehensive clubfoot release versus the Ponseti method: Which is better? Clin Orthop Relat Res 472(4):1281-1290.

18. Haj Zargar R, Baghdadi T, Ramezan M, Abdi R, Aslani H (2016) Modified Ponseti method of treatment for correction of neglected clubfoot in older children and adolescents-a preliminary report. J Pediatr Orthop B 25(2): 99-103.

19. Yagmurlu MF, Ermis MN, Akdeniz HE, Kesin E, Karakas ES (2011) Ponseti management of clubfoot after walking age. Pediatr Int 53(1): 85-89.

20. Digge V, Desai J, Das S (2018) Expanded age indication for Ponseti method for correction of congenital idiopathic talipes equinovarus: A systematic review. J Foot Ankle Surg 57(1):155-158.

21. Lourenço AF, Morcuende JA (2007) Correction of neglected idiopathic club foot by the Ponseti method. J Bone Joint Surg Br 89(3): 378-381.

22. Eidelman M, Kotlarsky P, Herzenberg JE (2019) Treatment of relapsed, residual and neglected clubfoot: Adjunctive surgery. J Child Orthop 13(3): 293-303.

For possible submissions Click below: 